\title{
Molecular epidemiology of human papillomavirus among HIV infected women in developing countries: systematic review and meta-analysis
}

\author{
Agajie Likie Bogale ${ }^{1 *}$, Nega Berhe Belay ${ }^{2}$, Girmay Medhin ${ }^{2}$ and Jemal Haidar Ali $^{3}$
}

\begin{abstract}
Background: Although, there is a variable burden of human papillomavirus (HPV) in women infected with HIV in developing countries, there are few studies that attempted to surmise such variable evidences. This review aimed to estimate the pooled prevalence of HPV genotype distribution and risk factors contributing to HPV infection among women infected with HIV in low- and middle-income countries.

Methods: We conducted a systematic review and meta-analysis of studies conducted in developing countries and reported HPV prevalence. We searched electronic databases: PubMed/Medline, SCOPUS, ScienceDirect, Excerpta Medical Database from Elsevier, Web of science, Cumulative Index of Nursing and allied Health Sciences and Google scholar databases to retrieve primary studies published in English language till 11th August 2019. We used randomeffects model to estimate the pooled prevalence of HPV genotypes, and funnel plot to assess publication bias. The registration number of this review study protocol is CRD42019123549.
\end{abstract}

Results: We included nineteen studies with a total of 8,175 participants in this review. The prevalence of HPV was extremely heterogeneous across the studies $\left(x^{2}=3782.80, p\right.$ value $\left.<0.001, I^{2}=99.6 \%\right)$. The estimated pooled prevalence of all HPV genotypes was $63.0 \%$ (95\% Cl: 48.0-78.0) while the pooled prevalence of high risk and low risk HPV genotypes were $51.0 \%$ (95\% Cl: $38.0-63.0)$ and $28.0 \%$ (95\% Cl: 12.0-43.0), respectively. The pooled prevalence of HPV genotype 16 was 20\%, while genotype 18 and 52 were $15 \%$ and $13 \%$, respectively. Different risk factors reported for HPV infection and the frequently reported were low CD4 count below 200 cells $/ \mathrm{mm}^{3}$ and high HIV viral load.

Conclusion: The pooled prevalence of HPV among HIV infected women in low- and middle-income countries was considerable and the proportion of high risk HPV genotypes were high when compared with low risk genotypes. Therefore, it is essential for the HPV prevention program to prevent the double burden of HPV and HIV in women.

Keyword: Human papillomavirus, Human immunodeficiency virus, Genotype, Women/females, Meta-analysis, Developing countries

*Correspondence: agalb.2000@yahoo.com

${ }^{1}$ Ethiopian Public Health Institute, and Addis Ababa University, P.O. Box 1242, Addis Ababa, Ethiopia

Full list of author information is available at the end of the article

\section{Background}

The papillomavirus is a heterogeneous group of DNA virus with circular, non-enveloped, double-stranded DNA genomes $[1,2]$. This virus infects humans and different species of animals [2]. The virus is discovered from the horn of Cottontail rabbit at the beginning of 1930s [3] and also revealed as a main cause of human cervical 
cancer in 1970s [4]. More than 300 papillomaviruses have been identified and completely sequenced, including over 200 human papillomaviruses [5]. The high-risk carcinogenic types of HPV currently designated by the International Agency for Research on Cancer (IARC) are HPV16, HPV18, HPV31, HPV33, HPV35, HPV39, HPV45, HPV51, HPV52, HPV56, HPV58, and HPV59. The HPV68 is classified as probably carcinogenic, and HPV26, HPV30, HPV34, HPV53, HPV66, HPV67, HPV 69, HPV70, HPV73, HPV82, HPV85, and HPV97 have been associated with rare cases of cervical cancer and are considered probable carcinogens [6, 7]. Genotype 6 and 11 are low-risk types that cause genital and skin warts [8]. Genital HPV infections are very common and prevalent in the age range of 18 to 30 years $[9,10]$. Infection of the cervix with HPV is necessary to cause cervical neoplasia and cervical cancer $[11,12]$, and integration of viral DNA into the host genome is necessary for persistent infection which could lead to the development of cervical dysplasia [11].

The prevalence of HPV is variable across the world. The study reported from developed countries indicate that the prevalence of HPV was 11 to $12 \%$ [13]. The recent global estimate indicates $11.7 \%$ of the HPV infection burden in the world [14]. The occurrence of about $85 \%$ of infected cases and $88 \%$ of the deaths due to cervical cancer is in developing countries [11].

The highest prevalence was reported in sub-Saharan Africa (24\%), Eastern Europe (21\%) and Latin America (16\%) [15].

The burden of HPV infection is higher in HIV infected women (50.8\%) than un-infected (22.6\%) [16] and 78.8\% among HIV infected than $34.4 \%$ of un-infected women [17]. Similarly, high-risk oncogenic HPV types is higher among HIV infected than un-infected women $(48.4 \%$ vs. $17.3 \%$ ) [16]. Other studies reported a prevalence of $68.0 \%$ [18] and 33.2\% [19]. Moreover, the study reported from developing countries indicated extremely variable prevalence of HPV that ranges from 20 to $70 \%$ [20]. The prevalence of low-risk HPV types were 3.6 to 5.6 times higher in HIV-sero-positive women when compare to HIV seronegative's [8].

Several risk factors are reported to be associated with HPV infection and these include HIV infection, other STIs (e.g., chlamydia, herpes simplex virus), and multiple sexual partners $[11,21]$. There are also other factors that mediate HPV infection such as cigarette smoking, oral contraceptive or hormonal contraceptive use, chronic inflammation and immunosuppressive conditions [10, 11, 21, 22]. Dietary factors, socioeconomic status, race/ ethnicity, geographic disparity and polymorphisms in the human leukocyte antigen system are additional factors that could mediate HPV infection [10, 11, 21, 22]. Being young age and having active sexual behavior are key risk factors for HPV acquisition and persistence of the infection [22].

HIV infection increases the risk of cervical infection due to high-risk HPV genotypes that induces high-grade cervical squamous intraepithelial lesions (HSILs), which in turn leads to the development of pre-invasive cervical lesions and invasive cervical cancer (ICC) [23-25]. HIV infection could alter the natural history of HPV infection through decreasing the self-clearance rate of infection and increasing progression to high grade and invasive lesions [24]. Furthermore, the incidence of HPV infection is three times higher in HIV-positive women [25], and can cause cervical cancer than their counterparts [26]. Nonetheless, with the exception of the systematic review and meta-analysis done in Kenya [27], evidences in this regard showing the burden and molecular distribution of HPV in low and middle income countries (LMICs) is limited [28]. Therefore, this review aims to fill the identified gaps by estimating the pooled prevalence of HPV, and investigating the factors associated with HPV infection among HIV infected women in LMICs.

\section{Methods}

\section{Search strategy and screening of papers}

We conducted a systematic review and meta-analysis of published articles to estimate the pooled prevalence of HPV in LMICs. We systematically searched the papers published in the following electronic databases; PubMed/MEDLINE, SCOPUS, Science Direct, Excerpta Medical Database from Elsevier (EMBASE), Web of science, Cumulative Index of Nursing and Allied Health Sciences (CINAHL) and Google scholar. The review was conducted in accordance with Preferred Reporting Items for Systematic Reviews and Meta-Analyses (PRISMA) standard [29]. We used a search strategy by combining the following key terms: molecular, molecular epidemiology, human papillomavirus, or HPV, papillomavaridae, Human immunodeficiency virus (HIV), AIDS (acquired human immunodeficiency syndrome), HIV infected, HIV positive, HIV sero-reactive, women, female and girl. We used Truncation(*) to manage spelling variation during search: infect" or positive, wom"n or female* or girl*. We used both free text and Medical subject heading [MeSH] terms during electronic database search.

PubMed database search strategy was:(((molecular [tiab] OR "Molecular Epidemiology"[Mesh]) AND ((Human papillomavirus[tiab] OR HPV[tiab]) OR "papillomaviridae"[MeSH Terms])) AND (((Human immunodeficiency virus[tiab] OR HIV[tiab]) OR "hiv"[MeSH Terms]) OR "hiv"[MeSH Terms])) AND (infected[tiab] OR positive[tiab])) AND (((women[tiab] OR females[tiab]) OR "women"[MeSH Terms]) OR "female"[MeSH Terms]) 
AND (("1966/01/01"[PDAT]: "2019/08/11"[PDAT]) AND "humans"[MeSH Terms] AND English[lang] AND "female"[MeSH Terms]).

The search was repeated to identify the consistency of search terms and results. Two authors independently reviewed the titles, abstracts and full articles of the retrieved studies.

\section{Study inclusion and exclusion criteria}

We included a cross sectional and cohort studies conducted in LMICs based on World Bank Country Classifications, 2018 [30] and that reported prevalence of HPV genotypes. The inclusion was restricted to the papers published in English language without limiting publication year till 11th August 2019. We excluded studies that did not clearly state the study design, outcome measured, the study conducted on HIV negative women alone, conducted in high-income countries, and the study reported HPV genotype from anal and oral organ types (Fig. 1).

\section{Study quality assessment}

We assessed the quality of included studies by using the 14 items Quality Assessment Tool for Observational Cohort and Cross-Sectional studies NHLBI, NIH [31]. This assessment tool mainly focused on research question, study population, eligibility criteria (inclusion and exclusion criteria of study participants), sample size justification, exposure measures and assessment, sufficient time frame to see an effect, outcome measures and blinding of outcome assessors, follow up rate, and statistical analysis. The quality assessment was rated as good, fair and poor based on the quality assessment tool criteria. The maximum score indicating high quality was 14 and

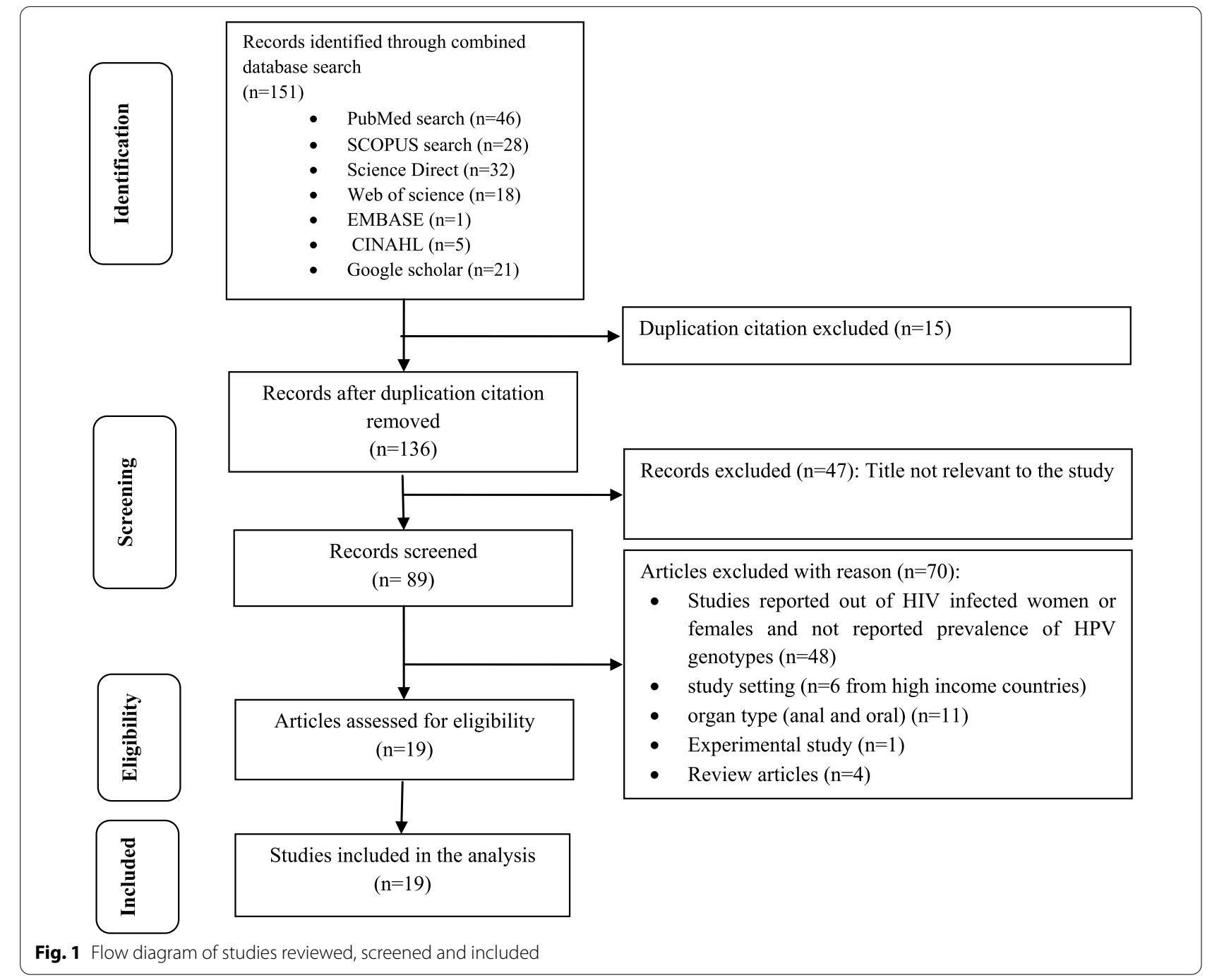


the lowest possible score was zero. The rating values of the included studies in terms of their quality were based on their design. Cross-sectional type do not consider the items which fit for cohort and taken as not-applicable (NA) and thus, the rating values were not taken from the possible maximum score (i.e. 14). In this review, all scores are written in percentage.

\section{Data extraction}

Data from eligible abstract and/or full text of the articles were extracted by considering the outcome variables (i.e. prevalence or proportion of HPV genotypes, magnitude of cancer causing HPVs or high risk (HR) HPV genotypes and low-risk HPV types), and factors that could potentially be associated with these outcomes. The characteristics of study participants of an eligible paper such as age range, mean or median age, sex, HIV sero-status, the prevalence of HPV genotype were also extracted. Study characteristics such as first author, year of publication, study duration, study setting, study location or country, study design, sample size were also extracted (Table 1). Other extracted data include the prevalence of different HPV genotypes (Table 2), factors which could potentially be associated with HPV infection and diagnostic methods applied to detect HPV infection (Table 3).

The majority of the studies included in our review had more than eighty percent and the lowest score observed was $62.5 \%$ in terms of quality. There was however one abstract included in the review, which was difficult to assess the quality of the article (Table 3 ).

\section{Statistical analysis}

We estimated the pooled prevalence of HPV with its 95\% Confidence Interval (CI) using random effects meta-analysis model assuming the true effect size varies between studies [32]. The proportion of HPV reported in each study is multiplied by its sample size to express patients with HPV infection in number, and data presented in forest plot. Heterogeneity in the prevalence of different studies was assessed using Chi-square $\left(\chi^{2}\right)$ based $\mathrm{Q}$ test with significant level of $p$ value $<0.1$ and $\mathrm{I}^{2}$. The $\mathrm{I}^{2}$ value of $25 \%$ indicates low heterogeneity while $50 \%$ moderate and $75 \%$ high [33]. The potential publication bias was assessed using a funnel plot. If the $95 \%$ of the point estimate of studies lie within the funnel plot defined by straight lines, then that indicates the absence of heterogeneity [34]. The potential sources of heterogeneity were assessed by doing subgroup analysis and moment based meta regression. Meta-regression extends subgroup analyses and allows to estimate effect size. Data analysis was conducted using STATA version 14.

\section{Results}

\section{Study characteristics}

We included 19 studies in our review (Fig. 1). These studies were reported from Rwanda [36, 37], Brazil [38-40], Nigeria [41, 42] Thailand [43], South Africa [44-47], Zambia [48], Burkinafaso [35, 49], Senegal [23] and Colombia [50,51]. There was one study conducted in two countries Burkinafaso and South Africa [52]. Five studies were from South America (three from Brazil and two from Colombia), one study from Asia (Thailand) and the rest were from African countries. All of the studies were from health facilities (Hospital and clinic) and the majority were cross sectional studies. The publication year varied from 2003 to 2017 while the majorities (13 articles) were published after 2009. Eight studies were published in 2013 and 2014. The maximum sample size was 1371 [44] and the minimum was 98 [41]. The age of participants ranged from 14 to 73 years $[39,50]$. Three studies didn't mention the upper age range of the participants $[23,36,42]$ (Table 1).

\section{Pooled prevalence of HPV}

We pooled data from 8175 HIV infected women to estimate the pooled prevalence of HPV infection using metaanalysis. The overall pooled prevalence of all types of HPV infection was $63.0 \%$ (Fig. 2) with high heterogeneity across the studies $\left(\chi^{2}=3,782.80\right.$ (d.f. $\left.=15\right) ; p$ value $<0.001$ and $\mathrm{I}^{2}=99.6 \%$ ). The pooled prevalence of high risk HPV was $51.0 \%$ (Fig. 3) with heterogeneity of $X^{2}=1069.84$ (d.f. $=12) ; p$ value $<0.001$ and $\mathrm{I}^{2}=98.88 \%$. Similarly, the estimated pooled prevalence of low risk HPV was $28.0 \%$ (Fig. 4) with heterogeneity of $X^{2}=296.83$; (d.f. $\left.=5\right) ; p$ value $<0.001$ and $\mathrm{I}^{2}=98.32 \%$.

The pooled prevalence of high risk HPV genotypes was also estimated in the studies (i.e. HPV genotypes $16,18,26,31,33,35,39,45,51,52,53,56,58,59,66$, $67,68,69,70,73$, and 82 ). The highest prevalence was observed for genotype 16 (20\%) followed by 18 (15\%) and 52 (13\%). Almost all genotypes indicated heterogeneity and the highest heterogeneity was observed in genotype $16\left(\mathbf{I}^{2}=98.53 \%\right)$ followed by $18\left(\mathbf{I}^{2}=97.18 \%\right)$ and 31 $\left(\mathbf{I}^{2}=96.17 \%\right)$ (Table 4$)$. The HPV genotypes $26,67,69,70$, 73 and 82 reported less frequently in the included studies which is difficult to interpret.

\section{Subgroup analysis}

The result of subgroup analysis based on the continent from where the studies were include shows significant heterogeneity between and within the group. The pooled prevalence of HPV in African was 69.0\% (95\% CI: 49.0-89.0) with heterogeneity of $\mathbf{I}^{2}=99.74 \%$ and $p$ 
Bogale et al. Virol J ～(2020) 17:179

Page 5 of 15

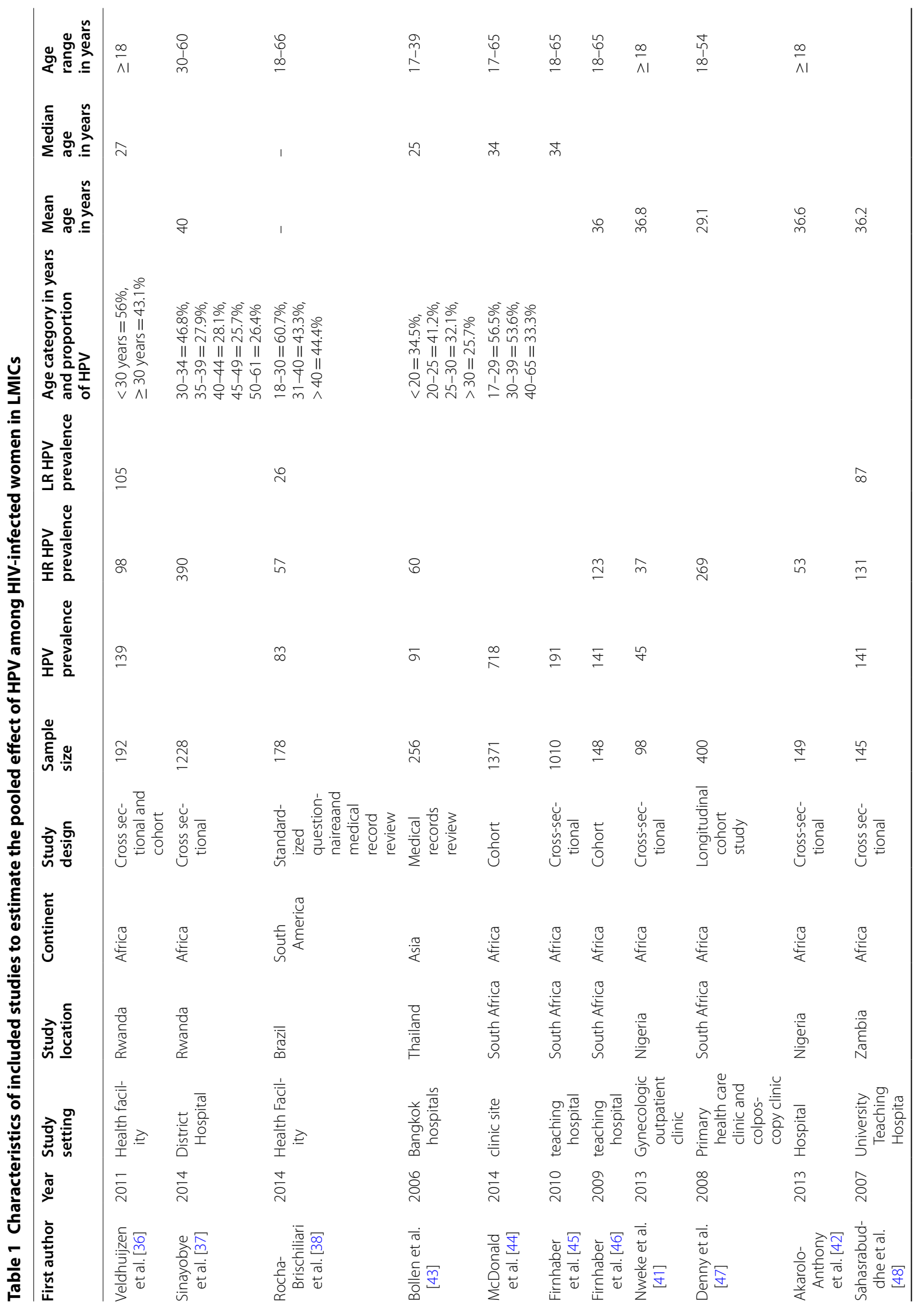




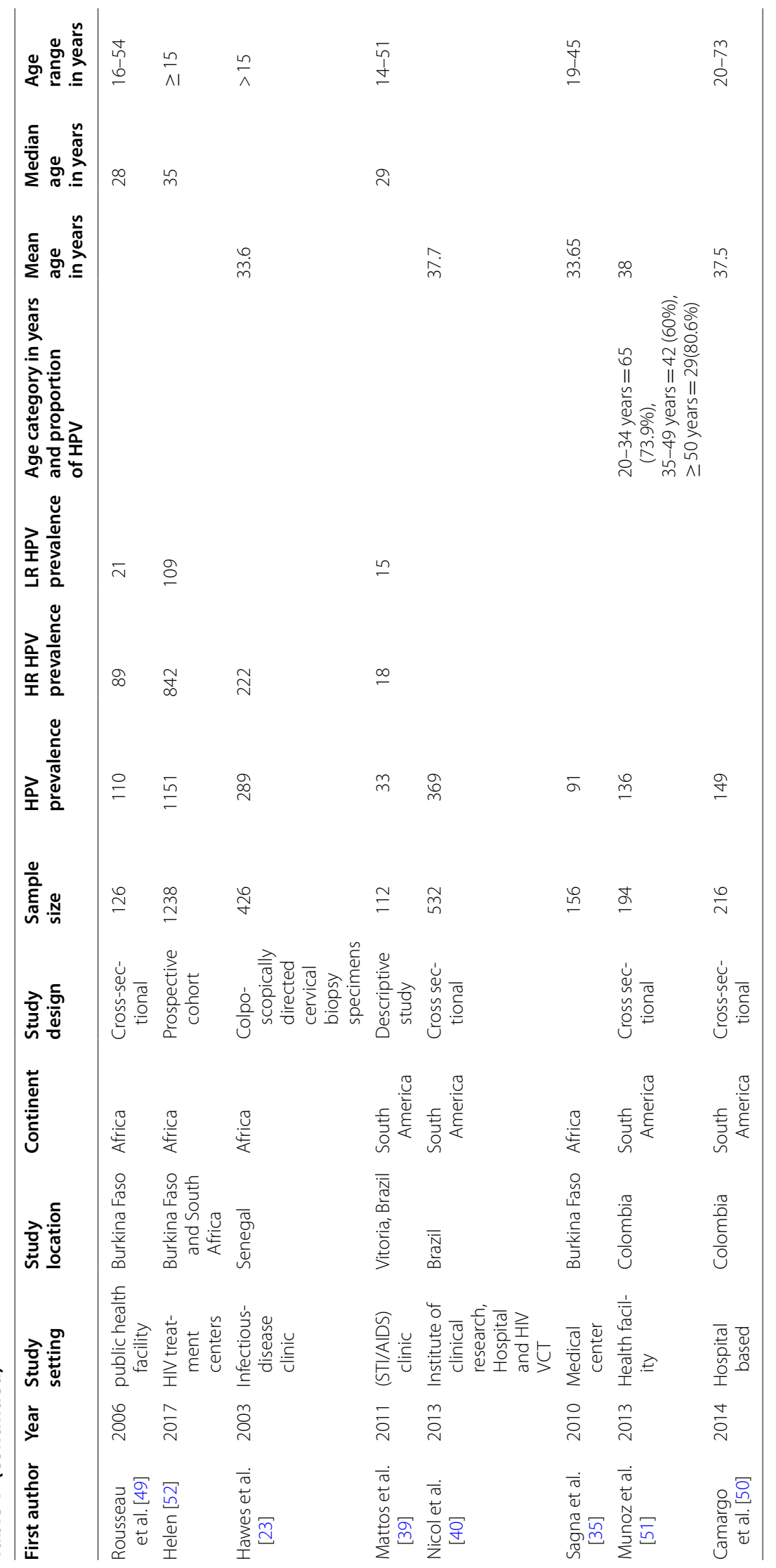




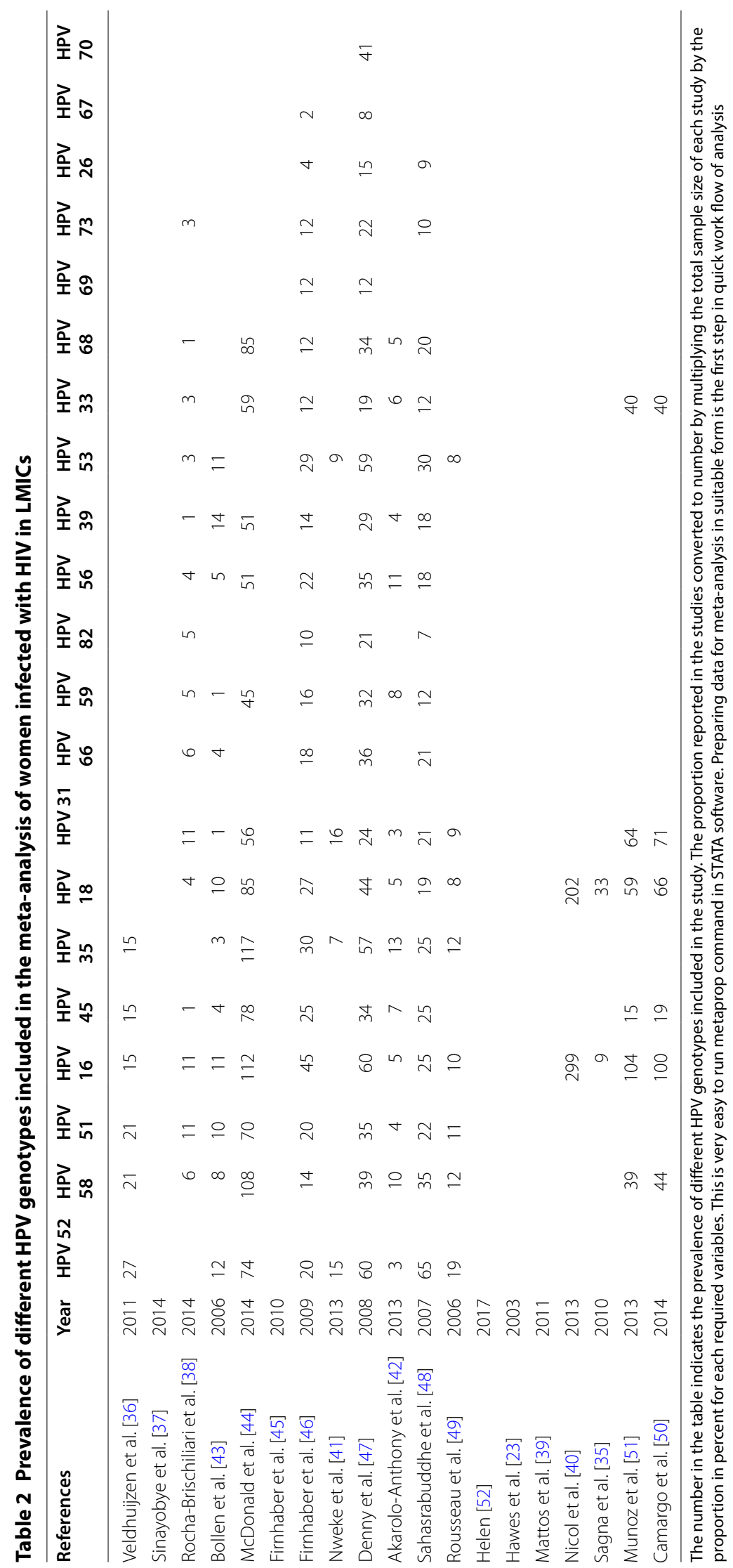


Table 3 Molecular genotyping techniques and associated factors for HPV infection

\begin{tabular}{|c|c|c|c|c|}
\hline References & $\begin{array}{l}\text { Year } \\
\text { of publication }\end{array}$ & $\begin{array}{l}\text { Molecular technique used } \\
\text { for genotyping }\end{array}$ & Associated factors & $\begin{array}{l}\text { Quality } \\
\text { assessment } \\
\text { score }\end{array}$ \\
\hline Veldhuijzen et al. [36] & 2011 & Linear Array HPV Genotyping Test (LA) & & $84.6 \%$ \\
\hline Sinayobye et al. [37] & 2014 & careHPV & $\begin{array}{l}\text { Lower CD4 count }<200 \text {, history of } 3 \text { or } \\
\text { more sexual partners, and history of using } \\
\text { hormonal contraception }\end{array}$ & $87.5 \%$ \\
\hline Rocha-Brischiliari et al. [38] & 2014 & $\begin{array}{l}\text { Genotyping using PCR-restriction fragment } \\
\text { length polymorphism analysis }\end{array}$ & $\begin{array}{l}\text { Hormonal contraceptive use and current } \\
\text { smoker }\end{array}$ & $100 \%$ \\
\hline Bollen et al. [43] & 2006 & Reverse line-blot hybridization & Higher HIV-plasma viral load & $87.5 \%$ \\
\hline McDonald et al. [44] & 2014 & $\begin{array}{l}\text { Prototype polymerase chain reaction (PCR)- } \\
\text { based line blot assay and PCR-based, } \\
\text { LinearArrayHPVTypingAssay }\end{array}$ & & $83.3 \%$ \\
\hline Firnhaber et al. [45] & 2010 & Linear Array genotyping assay (Roche) & & $87.5 \%$ \\
\hline Firnhaber et al. [46] & 2009 & Roche Linear Array HPV genotyping test & & $91.7 \%$ \\
\hline Nweke et al. [41] & 2013 & HPV GenoArray test kits & & $75.0 \%$ \\
\hline Denny et al. [47] & 2008 & Roche Linear Array HPV genotyping test & Low CD4 count and high viral load & $83.3 \%$ \\
\hline Akarolo-Anthony et al. [42] & 2013 & Roche Linear Array HPV Genotyping Test & & $87.5 \%$ \\
\hline Sahasrabuddhe et al. [48] & 2007 & Roche Linear Arrays HPV genotyping test & $\begin{array}{l}\text { HRHPV associated with low CD } 4 \\
\text { count }<200\end{array}$ & $75.0 \%$ \\
\hline Rousseau et al. [49] & 2006 & INNO-LiPA HPV Genotyping v2 test & High prevalence of HPV on HIV infection & $87.5 \%$ \\
\hline Helen [52] & 2017 & INNO-LiPA HPV genotyping Extra ${ }^{\circledR}$ assay & Injectable contraceptive and VL > 1000 & $91.7 \%$ \\
\hline Hawes et al. [23] & 2003 & PCR -based molecular tests & High VL and low CD4 count & $87.5 \%$ \\
\hline Mattos et al. [39] & 2011 & Restriction Fragment Length Polymorphism & & $75.0 \%$ \\
\hline Nicol et al. [40] & 2013 & VLPs-based ELISA & & $62.5 \%$ \\
\hline Sagna et al. [35] & 2010 & PCR -based molecular tests & & Only abstract \\
\hline Munoz et al. [51] & 2013 & PCR-based molecular tests & & $87.5 \%$ \\
\hline Camargo et al. [50] & 2014 & PCR-based molecular tests & $\begin{array}{l}\text { CD4 }<500 \text { and high } V L \text { have association } \\
\text { with HPV detection }\end{array}$ & $100 \%$ \\
\hline
\end{tabular}

HRHPV, high risk human papilloma virus; HIV, human immunodeficiency virus; VL, viral load; VLP, virus like particles; PCR, polymerase chain reaction; LiPA, line probe assay; ELISA, enzyme linked immuno-sorbant assay; CD4, cluster of differentiation 4

value $<0.001$. The pooled prevalence of HPV in South America was 57.0\% (95\% CI: 44.0-71.0) with heterogeneity of $\mathbf{I}^{2}=95.93 \%$ and $p$ value $<0.001$ ) (Fig. 5).

\section{Meta-regression analysis}

We assessed the effects of sample size and year of the study on heterogeneity between the studies using metaregression model. Both sample size and publication years significantly predicted the heterogeneity of the effect sizes (Table 5). In the adjusted model, both the sample size and publication year indicated heterogeneity in the effect size which is equivalent to the prevalence $(p<0.001)$. When we interpret the finding using $\beta$-coefficient, one unit increase in the sample size increases the effect size or the outcome of 1.04 points and the outcome decreases by 11.8 points for every one unit increase in the publication year (Table 5).

\section{Publication bias}

The funnel plot (widely used to examine bias in the results of meta-analysis) for the pooled prevalence of all genotypes HPV, high risk HPV and low risk HPV indicated that there is a publication bias (Fig. 6a-c). Figure $6 \mathrm{a}$, indicates the funnel plot of the 16 estimates of the HPV types available for meta-analysis (SE-Standard error, ES-Effect size: prevalence), (b) Funnel plot of the 13 estimates of high risk HPV types available for meta-analysis (SE-Standard error, ES-Effect size: prevalence), (c) Funnel plot of the 6 estimates of low risk HPV types available for meta-analysis (SE-Standard error, ES-Effect size: prevalence). The majority of included studies were out of $95 \%$ confidence limit. The outer dashed lines indicate the triangular region within which $95 \%$ of studies are expected to lie in the absence of both biases and heterogeneity. In this funnel plot, scatter properties of the included studies made by medium small size with white background color and the scale of 1 .

\section{Laboratory techniques applied to detect HPV infection in the included studies}

Molecular genotyping and HPV detection techniques applied for selected studies were Linear Array HPV 


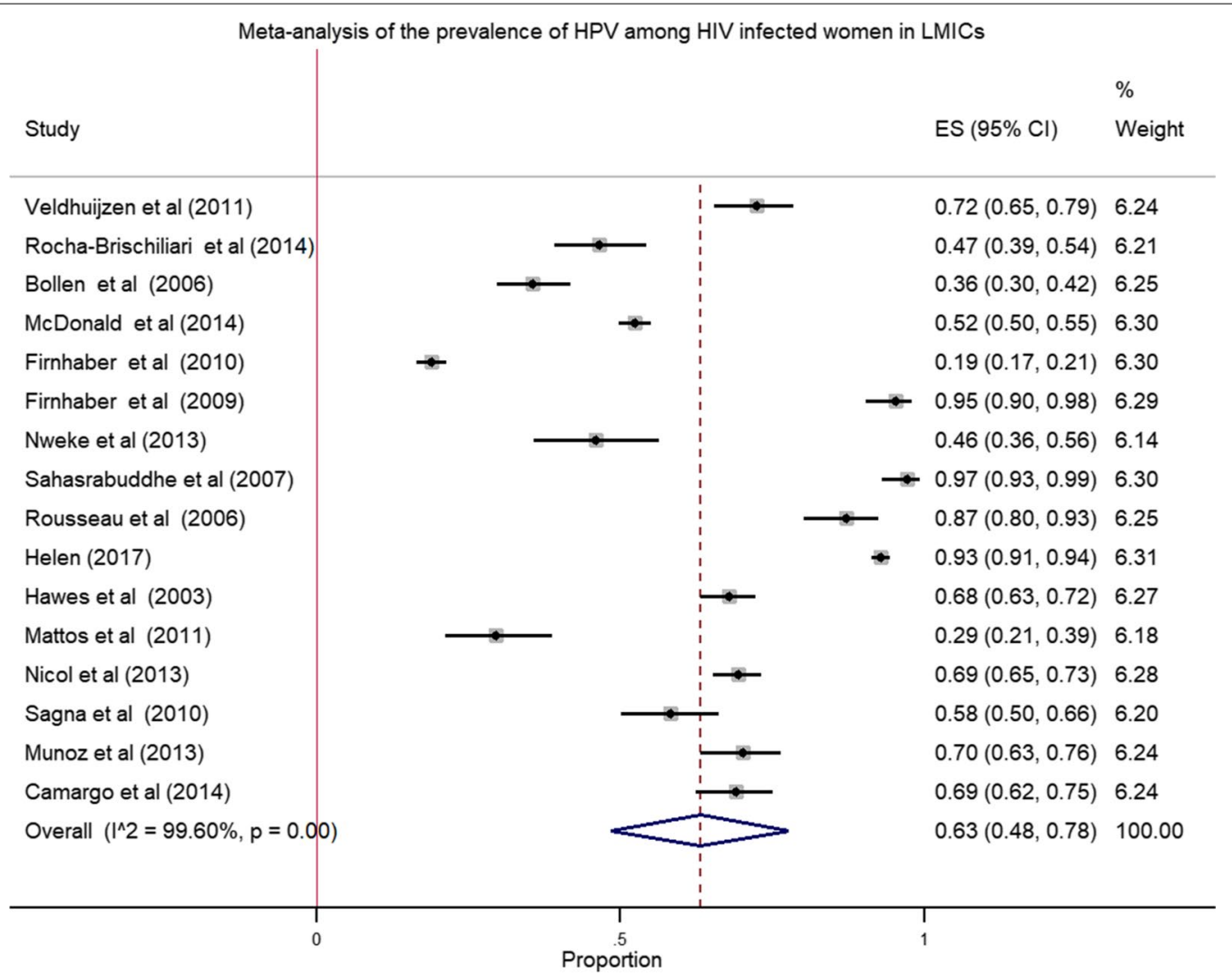

Fig. 2 Forest plot to estimate the pooled prevalence of human papillomavirus infection among HIV infected women with $95 \% \mathrm{Cl}$ (the estimate weighted based on random effects model): ES-Effect Size equivalent to prevalence, $\mathrm{Cl}$-confidence interval. In the plot, the diamond shows the pooled result and the boxes show the effect estimates from the single studies. The purple dotted vertical line indicates pooled estimate. The purple solid vertical line indicates the reference line at zero indicating no effect. The horizontal line through the boxes illustrate the length of the confidence interval and the boxes show the effect estimates from the single studies

Genotyping Test (LA), careHPV, genotyping using PCRrestriction fragment length polymorphism analysis, Reverse line-blot hybridization, INNO-LiPA HPV genotyping Extra ${ }^{\circledR}$ assay (Table 3).

\section{Factors associated with HPV infection}

High HIV viral load and low CD4 count were the most frequently reported factors that associated with high-risk HPV infection [23, 47, 48, 50]. Hormonal contraceptive use, CD4count $<200$ cells $/ \mathrm{mm}^{3}$, history of three or more sexual partners were reported as the factors associated with HPV infection [37, 38] (Table 3).

\section{Discussion}

In the current review, the pooled estimate of HPV infection prevalence was $63.0 \%$. The estimates of high risk and low risk genotypes were $51.0 \%$ and $28.0 \%$, respectively. Of high risk genotypes, HPV genotype 16 was high (20\%) followed by $18(15 \%)$ and $52(13 \%)$, respectively. Low CD4count and high HIV viral load were the risk factors that most frequently reported in this review.
This finding was lower than the findings in Kenyan which reported $68.0 \%$ overall pooled prevalence of high risk HPV among HIV positive women [27]. Genotype 16 was the most prevalent HPV genotype (20.0\%) in our review. This finding, however, was different from previous review which reported HPV 52 with pooled estimate prevalence of $26 \%$ among HIV infected women with normal cytology and HPV 16 which was $26 \%$ among women with abnormal cytology [27]. This difference is likely to be due to the number of included studies and the difference in the data included in the analysis, study setting and participants exposure to risk factors including HIV.

Lower CD4 count most frequently reported in this review is concordant with previous reviews in which low CD4 was strongly associated with HPV infection [5355]. Previous study also revealed that the most frequent high risk genotype observed in HIV positive women (i.e. 46.7\%) [54] which is closer to the current pooled estimate for high risk HPV (51.0\%), indicating that HIV infection might increase the susceptibility to latent HPV infection [55]. 


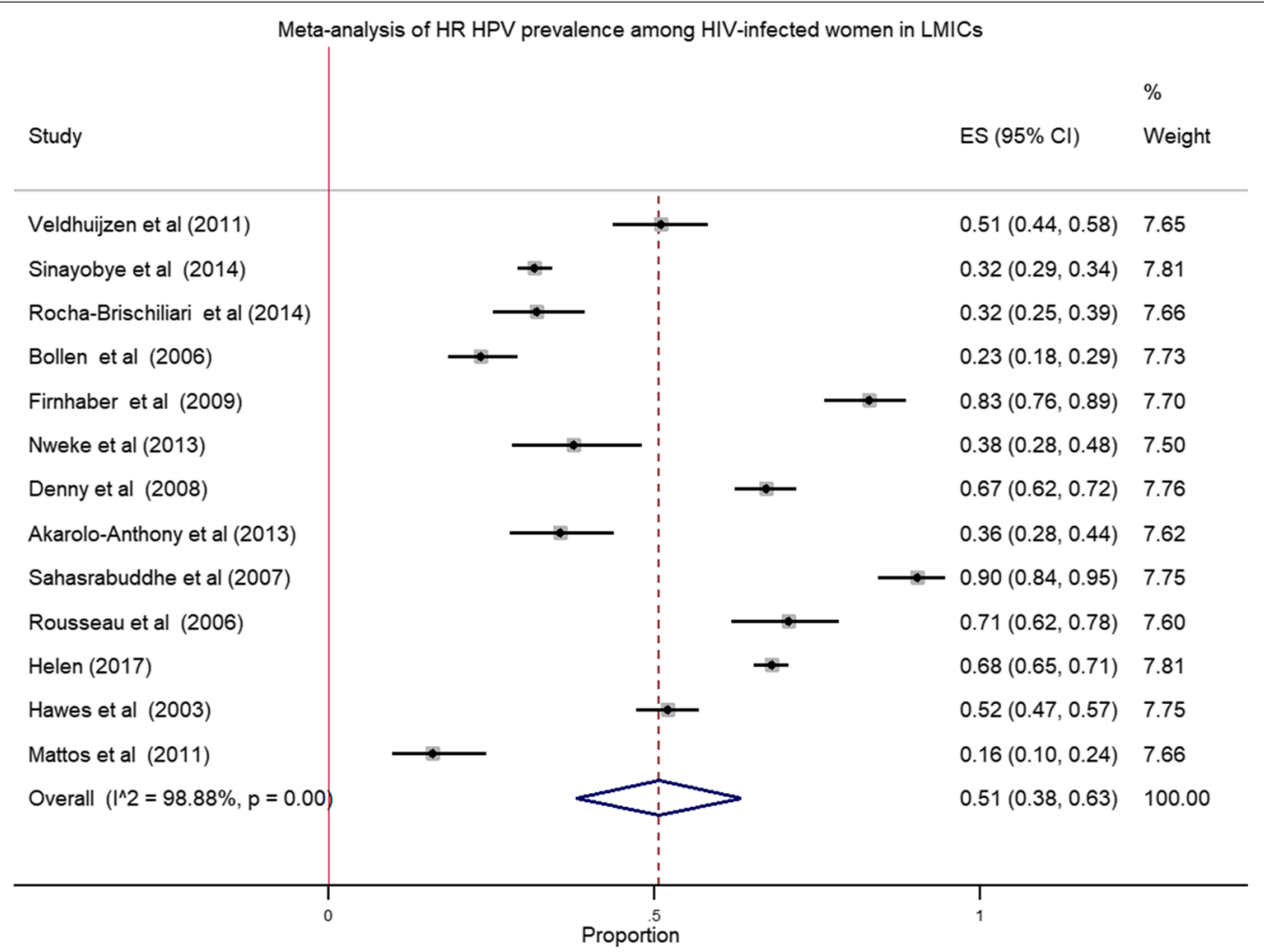

Fig. 3 Forest plot to estimate the pooled prevalence of high risk human papillomavirus infection among HIV infected women (the estimate weighted based on random effects model): ES—effect Size equivalent to prevalence, $\mathrm{Cl}$ —confidence interval. In the plot, the diamond shows the pooled result and the boxes show the effect estimates from the single studies. The purple dotted vertical line indicates pooled estimate. The purple solid vertical line indicates the reference line at zero indicating no effect. The horizontal line through the boxes illustrate the length of the confidence interval and the boxes show the effect estimates from the single studies

The review conducted to estimate prevalence of HPV genotype among African women, including Ethiopia revealed that HPV16, 52, 35, 18, 58, 51, 45, 31, 53, and 56 were the ten most common genotypes in the normal cervical cytology while HPV 16, 18, 35, and 52 were the four common types [56]. Another review from Ethiopian women depicted that HPV 16, 52, 18, 58, 45 were top five genotypes with the proportion of $45.3 \%, 9.4 \%, 8.2 \%, 6.9 \%$, $5.2 \%$, respectively [57]. Correspondingly, the pooled estimates of about 21 high risk HPV genotypes among HIV infected women were reported in this review with the estimated prevalence of genotype 16 (20\%), 18 (15\%), 52 (13\%), 31 and 58 (11\% each), 35 and 53 (10\% each), 33, 51, and 66 (8\% each), 45 (7\%), and the remaining genotypes had the pooled estimate of less than seven percent.

The original research article conducted in Korea reported prevalence of $16.7 \%$ with the high risk HPV type of $12.5 \%$ [58] which is too far up when compared with the pooled estimates of the current review which focused on HIV positive women. In addition, the study among Arab women indicated 6.2\% among Qatari women and 5.9\% non-Qatari women [59] somewhat concordant with the study conducted in Lebanon which reported HPV prevalence of $6.7 \%$ [60]. This variation is probably attributed to the differences in the study settings, sample sizes used and the studied population.

Our finding indicated heterogeneity on the outcome variable which is the effect size equivalent to the prevalence of HPV genotypes. Therefore, careful interpretation of the heterogeneity chi-square test (variation in effect estimates beyond chance) is required, since it has low power in the situation of a meta-analysis when studies have a small sample size or are few in number. It is worth noting at this junction that while a statistically significant result may indicate a problem with heterogeneity, a nonsignificant result must not be taken as evidence of no heterogeneity.

\section{Strength and limitations of the study}

This review is conducted by searching more than five biomedical databases and a large number of pooled participants are involved in the study. Another strength is that this review assessed HPV prevalence studies among HIV infected women in developing countries at large and 


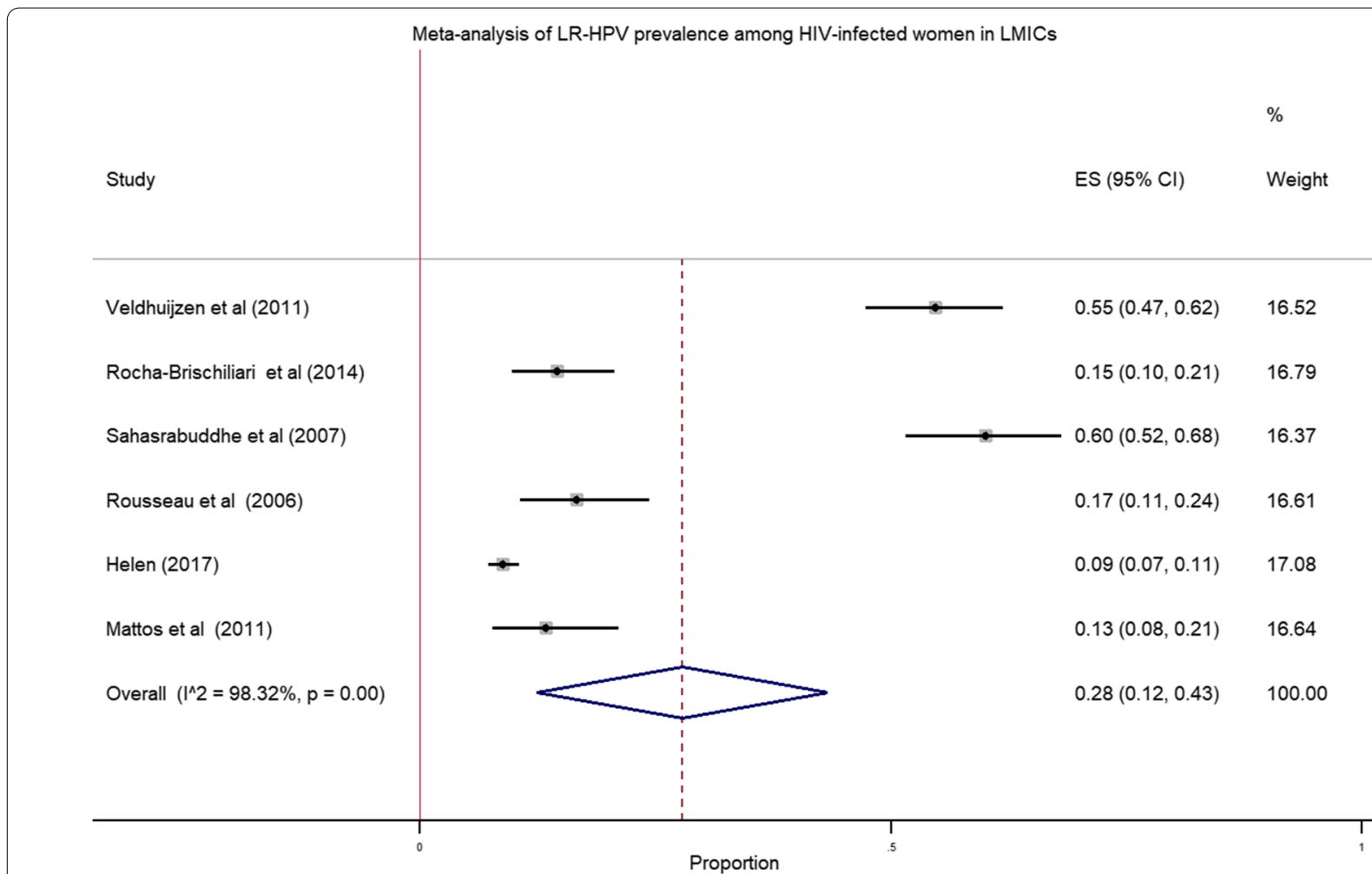

Fig. 4 Forest plot to estimate the pooled prevalence of low risk human papillomavirus infection among HIV infected women with $95 \% \mathrm{Cl}$ (the estimate weighted based on random effects model): ES—effect size equivalent to prevalence, Cl—confidence interval. In the plot, the diamond shows the pooled result and the boxes show the effect estimates from the single studies. The purple dotted vertical line indicates pooled estimate. The purple solid vertical line indicates the reference line at zero indicating no effect. The horizontal line through the boxes illustrate the length of the confidence interval and the boxes show the effect estimates from the single studies

Table 4 The pooled prevalence of different genotypes of HPV among HIV-infected women in LMICs

\begin{tabular}{|c|c|c|c|c|c|c|}
\hline HPV genotypes & Random effects pooled \%ES (95\% Cl) & No of studies & $x^{2}$ & DF & $p$ value & $I^{2}(\%)$ \\
\hline 16 & $20(12.0-28-0)$ & 13 & 814.56 & 12 & $<0.001$ & 98.53 \\
\hline 18 & $15(10.0-20.0)$ & 12 & 390.48 & 11 & $<0.001$ & 97.18 \\
\hline 26 & $4(2.0-5.0)$ & 3 & 2.12 & 2 & 0.35 & 5.68 \\
\hline 31 & $11(7.0-14.0)$ & 11 & 260.91 & 10 & $<0.001$ & 96.17 \\
\hline 33 & $8(5.0-11.0)$ & 8 & 72.55 & 7 & $<0.001$ & 90.35 \\
\hline 35 & $10(6.0-14.0)$ & 9 & 120.78 & 8 & $<0.001$ & 93.38 \\
\hline 39 & $5(3.0-8.0)$ & 7 & 53.68 & 6 & $<0.001$ & 88.82 \\
\hline 45 & $7(5.0-10.0)$ & 10 & 114.13 & 9 & $<0.001$ & 92.11 \\
\hline 51 & $8(5.0-10.0)$ & 9 & 37.74 & 8 & $<0.001$ & 78.80 \\
\hline 52 & $13(9.0-18.0)$ & 9 & 157.30 & 8 & $<0.001$ & 94.91 \\
\hline 53 & $10(5.0-16.0)$ & 7 & 83.80 & 6 & $<0.001$ & 92.84 \\
\hline 56 & $6(4.0-9.0)$ & 7 & 45.42 & 6 & $<0.001$ & 86.79 \\
\hline 58 & $11(8.0-14.0)$ & 11 & 94.54 & 10 & $<0.001$ & 89.42 \\
\hline 59 & $5(3.0-7.0)$ & 7 & 66.49 & 6 & $<0.001$ & 90.98 \\
\hline 66 & $8(3.0-12.0)$ & 5 & 44.36 & 4 & $<0.001$ & 90.98 \\
\hline 67 & $2(1.0-3.0)$ & 2 & & 1 & & \\
\hline 68 & $6(3.0-10.0)$ & 6 & 74.28 & 5 & $<0.001$ & 93.27 \\
\hline 69 & $4(2.0-5.0)$ & 2 & & 1 & & \\
\hline 70 & & 1 & & & & \\
\hline 73 & $5(2.0-8.0)$ & 4 & 12.73 & 3 & 0.01 & 76.42 \\
\hline 82 & $5(3.0-6.0)$ & 4 & 3.54 & 3 & 0.32 & 15.21 \\
\hline
\end{tabular}

$\mathrm{HPV}$, human papillomavirus; $\mathrm{X}^{2}$, heterogeinity chi-square; $\mathrm{DF}$, degree of freedom; $\mathrm{I}^{2}$, heterogeneity; $\mathrm{ES}$, effect size, $\mathrm{Cl}$, confidence interval 


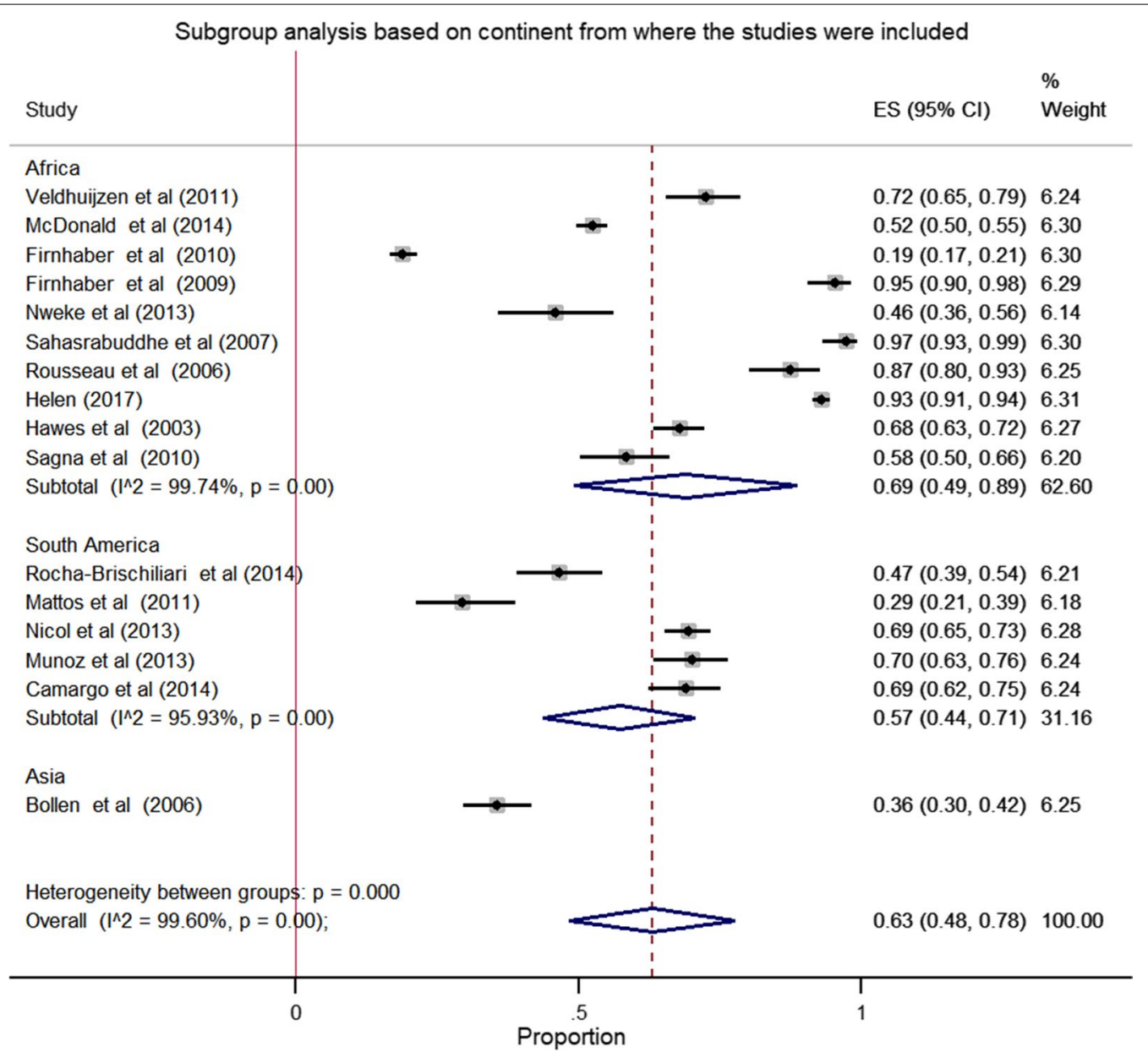

Fig. 5 Forest plot of the subgroup analysis based on continent from where the studies were reported. In this plot, three diamond shapes are observed. The first two indicates subtotal prevalence's and the third one indicates the pooled estimate of the prevalence of HPV

reported pooled estimates of all HPV genotypes, high risk HPV genotype and low risk HPV. The limitation of this study was inclusion of studies published only in English language. This could be one of the possible causes for observed publication bias and heterogeneity of the estimated effects.

Table 5 Meta-regression analyses for year of study and sample size as a reason of heterogeneity on the prevalence of HPV among HIV-infected women in LMICs

\begin{tabular}{lccc}
\hline Variable & \multicolumn{2}{l}{ Adjusted model } & \\
\cline { 2 - 4 } & $\boldsymbol{B ( 9 5 \% ~ C l )}$ & SE & $\boldsymbol{p}$ value \\
\hline Sample size & $1.04(1.0$ to 1.09$)$ & .02 & $<0.001$ \\
Publication year & $-11.8(-16.3$ to -7.2$)$ & 2.1 & $<0.001$
\end{tabular}

$\mathrm{SE}$, standard error; $ß$, regression coefficient; $\mathrm{Cl}, 95 \%$ Confidence interval

\section{Conclusion}

This review indicated that the pooled prevalence of all genotypes HPV and high risk HPV among HIV infected women in LMICs were considerable. To enhance the well-being of HPV/HIV co-infected women it is necessary to strengthen programs for diagnosis, treatment, and provide HPV vaccination based on common highrisk genotypes. 


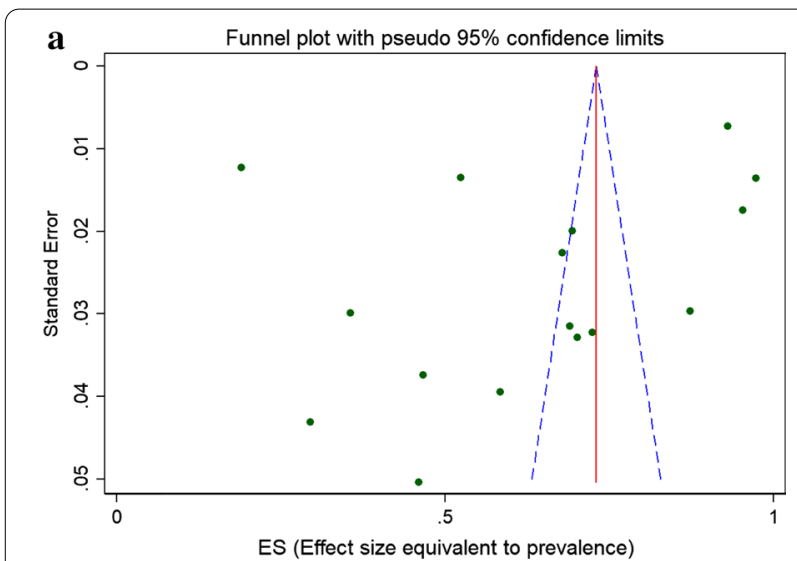

b
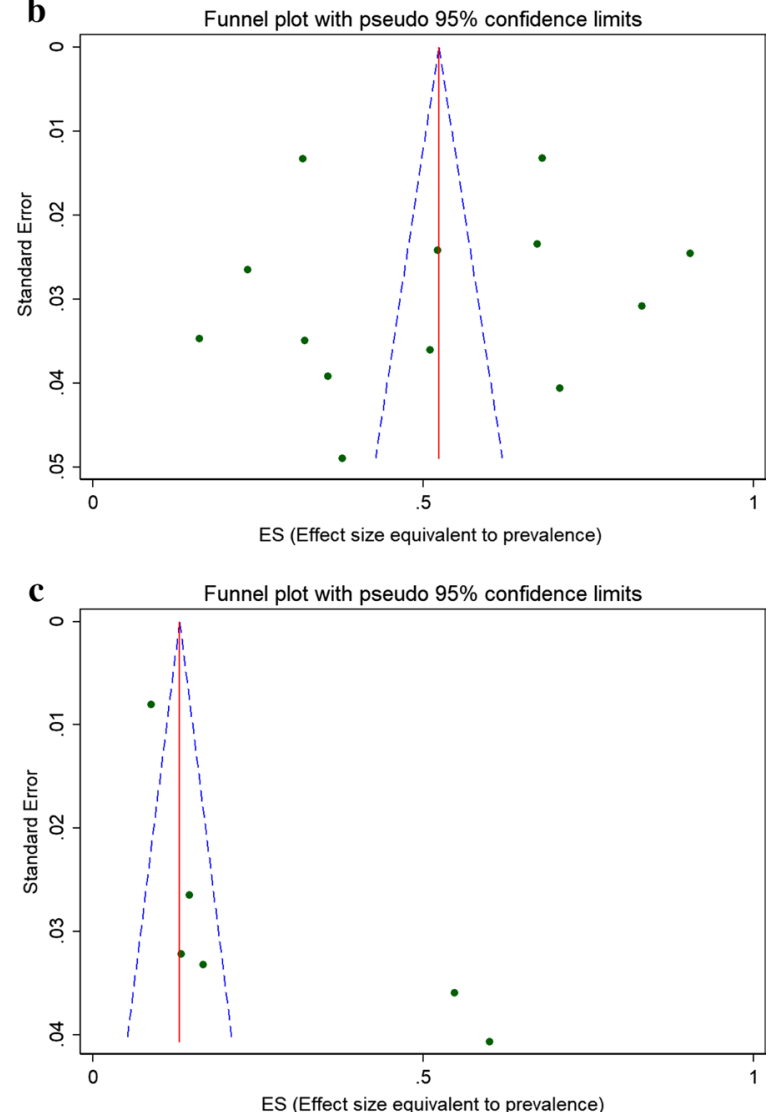

Fig. 6 Publication bias assessment: a funnel plot of the 16 estimates of HPV types available for meta-analysis (SE-standard error, ESeffect size: prevalence), $\mathbf{b}$ funnel plot of the 13 estimates of high risk HPV types available for meta-analysis, c funnel plot of the 6 estimates of low risk HPV types available for meta-analysis. In this plot, the blue broken line indicates Pseudo $95 \% \mathrm{Cl}$, the solid red line indicates pooled estimate of the prevalence of HPV, and the scattered circle dots indicates included studies in the meta-analysis. The scale on the $\mathrm{X}$-axis indicates Effect size estimate or proportion and the $\mathrm{Y}$-axis indicates the precision estimate using standard Error

\section{Abbreviations}

Cl: Confidence interval; df: Degree of freedom; DNA: Deoxyribonucleic acid; ELISA: Enzyme linked immuno-sorbant assay; ES: Effect size; HAART: Highly active anti retroviral therapy; HIV: Human Immunodeficiency virus; HPV: Human papillomavirus; HSILs: High grade squamous intraepithelial lesions; $1^{2}$ : Heterogeneity; ICC: Invasive cervical cancer; LMICs: Low and middle income countries; MeSH: Medical subject heading; PCR: Polymerase chain reaction; SILs: Squamous intraepithelial lesions; STI: Sexually transmitted infection; tiab: Title and abstract; VLP: Virus like particle.

\section{Acknowledgements}

The authors acknowledge the contribution of Aklilu Lemma Institute of Pathobiology, Addis Ababa University, Department of Tropical and Infectious Diseases and Ethiopian Public Health Institute for the opportunity to access an internet. In particular, authors like to thank Minilik Demesie and Habteyes Tolla, EPHI staff for their unreserved support for this review protocol.

\section{Authors' contributions}

Conceptualization: AL. Data curation: AL, GM. Formal analysis: AL, GM. Investigation: $\mathrm{AL}$ and JH. Methodology: $\mathrm{AL}, \mathrm{GM}, \mathrm{NB}, \mathrm{JH}$. Project administration: AL. Writing —original draft: AL. Writing—review and editing: GM, NB, JH. All authors read and approved the final manuscript.

\section{Authors' information}

The first author Agajie Likie Bogale (AL) is staff of Ethiopian Public Health Institute and currently PhD student at Aklilu Lemma Institute of Pathobiology, Addis Ababa University, Department of Tropical and Infectious Diseases; Nega Berhe Belay (NB) is senior instructor at Aklilu Lemma Institute of Pathobiology, Addis Ababa University, Department of Tropical and Infectious Diseases; Girmay Medhin (GM) is senior instructor of the course Advanced Research Methods and Biomedical Data Analysis; Professor Jemal Haidar Ali $(\mathrm{JH})$ is senior consultant and instructor at school of public health, Addis Ababa University, Ethiopia.

\section{Funding}

There is no fund for this review.

\section{Availability of data and materials}

All data generated or analyzed during this review are included in this article.

\section{Ethical approval and consent to participate.}

This review was based on previous published articles indicating that there is no need of ethical clearance. However, the protocol of this study was pre-registered on PROSPERO (International prospective register of systematic reviews) University of York, Centre for Reviews and Dissemination with registration number CRD42019123549.

\section{Consent for publication}

Not applicable.

\section{Competing interest}

There is no any competing interest.

\section{Author details}

${ }^{1}$ Ethiopian Public Health Institute, and Addis Ababa University, P.O. Box 1242, Addis Ababa, Ethiopia. ${ }^{2}$ Department of Tropical and Infectious Diseases, Aklilu Lemma Institute of Pathobiology, Addis Ababa University, P.O. Box 1176, Addis Ababa, Ethiopia. ${ }^{3}$ School of Public Health, College of Health Sciences, Addis Ababa University, 1000, P.O. Box 27285, Addis Ababa, Ethiopia.

Received: 22 May 2020 Accepted: 5 November 2020

Published online: 16 November 2020

\section{References}

1. Hoory T, Monie A, Gravitt P, Wu TC. Molecular epidemiology of human papillomavirus. J Formos Med Assoc. 2008;107(3):198-217. 
2. Terai M, Burk RD. Complete nucleotide sequence and analysis of a novel human papillomavirus (HPV 84) genome cloned by an overlapping PCR method. Virology. 2001;279:109-15.

3. Shope RE, Weston Hurst E. Infectious papillomatosis of rabbits. J Exp Med. 1933;58:607-24

4. Hausen HZ. Human papilloma viruses and their possible role in squamous cell carcinomas. Curr Top Microbiol Immunol. 1977:78:1-30.

5. Egawa N, Egawa K, Griffin H, Doorbar J. Human papillomaviruses; epithelial tropisms, and the development of neoplasia. Viruses. 2015;7(7):3863-90.

6. Arbyn M, Tommasino M, Depuydt C, Dillner J. Are 20 human papillomavirus types causing cervical cancer? J Pathol. 2014;234(4):431-5.

7. Groves IJ, Coleman N. Pathogenesis of human papillomavirus-associated mucosal disease. J Pathol. 2015;235(4):527-38.

8. Silverberg MJ, Ahdieh L, Munoz A, Anastos K, Klein RS, Massad S, et al. The impact of HIV infection and immunodeficiency on human papillomavirus type 6 or 11 infection and on genital warts. Sex Transm Dis. 2002;29(8):427-35.

9. Stanley M. Gynecologic oncology pathology and epidemiology of HPV infection in females. Gynecol Oncol. 2010;117(2):5-10.

10. Steben M, Duarte-Franco E. Human papillomavirus infection: epidemiology and pathophysiology. Gynecol Oncol. 2007;107:2-5.

11. Echelman D, Feldman S. Management of cervical pre cancers: a global perspective. Hematol Oncol Clin N Am. 2012;26(1):31-44.

12. Bosch FX, Lorincz A, Munoz N, Meijer CJ, Shah KV. The causal relation between human papillomavirus and cervical cancer. J Clin Pathol. 2002:55(4):244-65.

13. Forman D, de Martel C, Lacey CJ, Soerjomataram I, Lortet-Tieulent J, Bruni $L$, et al. Global burden of human papillomavirus and related diseases. Vaccine. 2012;30:12-23.

14. Tota JE, Chevarie-davis M, Richardson LA, de Vries M, Franco EL. Epidemiology and burden of HPV infectionand related diseases: implications for prevention strategies. Prev Med (Baltim). 2011;53:12-21.

15. UNAIDS. HPV, HIV and cervical cancer; 2016.

16. Remis RS, Liu J, Loutfy M, Tharao W, Rebbapragada A, Perusini SJ, et al. The epidemiology of sexually transmitted coinfections in HIV-positive and HIV-negative African-Caribbean women in Toronto. BMC Infect Dis. 2013;13:550.

17. Couture M, Page K, Stein ES, Sansothy N, Sichan K, Kaldor J, et al. Cervica human papillomavirus infection among young women engaged in sex work in Phnom Penh, Cambodia: prevalence, genotypes, risk factors and association with HIV infection. BMC Infect Dis. 2012;12:166

18. Lillo FB, Ferrari D, Veglia F, Origoni M, Grasso MA, Lodini S, et al. Human papillomavirus infection and associated cervical disease in human immunodeficiency virus - infected women: effect of highly active antiretroviral therapy. J Infect Dis. 2001;184:547-51.

19. Stuardo V, Agustí C, Godinez JM, Montoliu A, Torné A, Tarrats A, et al. Human papillomavirus infection in HIV-1 infected women in catalonia (Spain): implications for prevention of cervical cancer. PLoS ONE. 2012;7(10):1-9

20. Moodley M, Mould S. Invasive cervical cancer and human immunodeficiency virus ( HIV ) infection in KwaZulu-Natal, South Africa. J Obstet Gynaecol. 2005;25(7):706-10.

21. Zhu Y, Wang Y, Hirschhorn J, Zhao Z, Davis MR, Feldman S, et al. Human papillomavirus and its testing assays, cervical cancer screening, and vaccination, vol. 81. 1st ed. Amsterdam: Elsevier; 2017

22. Trottier H, Franco EL. The epidemiology of genital human papillomavirus infection. Vaccine. 2006;1:4-15.

23. Hawes SE, Critchlow CW, Niang MA, Diouf MB, Diop A, Touré P, et al. Increased risk of high-grade cervical squamous intraepithelial lesions and invasive cervical cancer among african women with human immunodeficiency virus type 1 and 2 infections. J Infect Dis. 2003;188:555-63.

24. Clarke B, Chetty R. Postmodern cancer: the role of human immunodeficiency virus in uterine cervical cancer. Mol Pathol. 2002;55:19-24.

25. Gheit T, Simoes RT, Tommasino M, Donadi EA, Gonçalves MA. Brief report HPV16 variants in squamous intraepithelial lesions in human immunodeficiency virus-negative and -positive Brazilian Women. Viral Immunol. 2006;19(2):340-5
26. Dreyer $\mathrm{G}$. Best practice \& research clinical obstetrics and gynaecology clinical implications of the interaction between HPV and HIV infections. Best Pract Res Clin Obstet Gynaecol. 2018;47:95-106.

27. Menon S, Wusiman A, Boily MC, Kariisa M, Mabeya H, Luchters S, et al. Epidemiology of HPV genotypes among HIV positive women in Kenya: a systematic review and meta-analysis. PLoS ONE. 2016;11(10):e0163965. https://doi.org/10.1371/journal.pone.0163965S.

28. Human papillomavirus and related diseases report, Ethiopia. June 2019.

29. PRISMA 2009 Checklist Section / topic PRISMA 2009 Checklist; 2009. pp. $1-2$.

30. World Bank Country Classifications. 2018. https://datahelpdesk.world bank.org/knowledgebase/articles/906519

31. Quality Assessment Tool for Observational Cohort and Cross-Sectional Studies; 2017. pp. 1-4

32. Borenstein M, Hedges LV, Higgins JPT, Rothstein HR. Introduction to meta analysis. New York: Wiley; 2009.

33. Higgins JPT, Thompson SG, Deeks JJ, Altman DG. Measuring inconsistency in meta-analyses. BMJ. 2003;327:557-60.

34. Sterne JAC, Harbord RM. Funnel plots in meta-analysis. Stata J. 2004:4(2):127-41.

35. Sagna T, Djigma F, Zeba M, Bisseye C, Karou SD, Ouermi D, et al. Human papillomaviruses prevalence and genital coinfectionsin HIV-seropositive women in Ouagadougou (Burkina Faso). Pak J Biol Sci. 2010;13(19):951-5.

36. Veldhuijzen NJ, Braunstein SL, Vyankandondera J, Ingabire C, Ntirushwa J, Kestelyn E, et al. The epidemiology of humanpapillomavirus infection in HIV-positive and HIV-negative high-risk women in Kigali, Rwanda. BMC Infect Dis. 2011:11:333.

37. Sinayobye JDA, et al. Prevalence and risk factors for High-Risk Human Papillomavirus (hrHPV) infection among HIV-infected and Uninfected Rwandan women: implications for hrHPV-based screening in Rwanda. Infect Agents Cancer. 2014:9:40.

38. Rocha-Brischiliaril SC, Gimenes F, de Abreu AL, Irie MM, Souza RP, Santana RG, et al. Risk factors for cervical HPV infection and genotypes distribution in HIV-infected South Brazilian women. Infect Agents Cancer. 2014:9:6. https://doi.org/10.1186/1750-9378-9-6.

39. de Mattos AT, de Freitas LB, Lima BMC, Miranda AE, Spano LC. Diversity and uncommon HPV types in HIV seropositive and seronegative women attending an sti clinic. Braz J Microbiol. 2011;42:786-93.

40. Nicola AF, Grinsztejnb B, Friedmanb RK, Velosob VG, Cunhab CB, Georgb I, et al. Seroprevalence of HPV vaccine types 6, 11, 16 and 18 in HIVinfected and uninfected women from Brazil. J Clin Virol. 2013;57:147-51.

41. Nweke IG, Banjo AAF, Abdulkareem FB, Nwadike VU. "Prevalence of human papilloma virus DNA in HIV positive women in Lagos University Teaching Hospital (LUTH) Lagos, Nigeria. Br Microbiol Res J. 2013;3(3):400-13.

42. Akarolo-Anthony, et al. HIV associated high-risk HPV infection among Nigerian women. BMC Infect Dis. 2013;13:521.

43. Bollen LJM, Chuachoowong R, Kilmarx PH, Mock PA, Culnane M, Skunodom N, et al. Immunodeficiency virus-infected pregnant thai women: implications for future HPV Immunization. Sex Transm Dis. 2006;33(4):259-64.

44. Mcdonald AC, Tergas Al, Kuhn L, Denny L, WrightJr TCW. Distribution of human papillomavirus genotypes among HIV-positive and HIV-negative women in Cape Town, South Africa. Front Oncol. 2014;4:1-11.

45. Firnhaber C, Van Le H, Pettifor A, Schulze D, Michelow P, Sanne IM, et al. Association between cervical dysplasia and human papillomavirus in HIV seropositive women from Johannesburg South Africa. Cancer Causes Control. 2010;21:433-43.

46. Firnhaber C, Zungu K, Levin S, Michelow P, Montaner LJ, McPhail P, et al. Diverse and high prevalence of human papillomavirus associated with a significant high rate of cervical dysplasia in human immunodeficiency virus-infected women in Johannesburg, South Africa. Acta Cytol. 2009;53:10-7

47. Denny L, Boa R, Williamson A, Allan B, Hardie D, Stan R, et al. Human papillomavirus infection and cervical diseasein human immunodeficiency virus-1-infected women. Obstet Gynecol. 2008;111(6):1380-7.

48. Sahasrabuddhe VV, Mwanahamuntu MH, Vermund SH, Huh WK, Stringer JSA, Parham GP, et al. Prevalence and distribution of HPV genotypes among HIV-infected women in Zambia. Br J Cancer. 2007;96:1480-3.

49. Rousseau MND, Nagot N, Martineau VC, Ouedraogo A, Konate I, Weiss HA, et al. Human papillomavirus genotype distribution and cervical 
squamous intraepithelial lesions among high-risk women with and without HIV-1 infection in Burkina Faso. Br J Cancer. 2006;95(3):355-62.

50. Camargo, et al. Human papillomavirus detection in women with and without human immunodeficiency virus infection in Colombia. BMC Cancer. 2014;14:451.

51. Munoz M, Camargo M, De Leon SCS, Sanchez R, Pineda-Peña AC, PerezPrados A, et al. Classical molecular tests using urine samples as a potential screening tool for human papillomavirus detection in human immunodeficiency virusinfected women. J Clin Microbiol. 2013;51:3688-93.

52. Kelly HA. The epidemiology of Human Papillomavirus (HPV) infection and epigenetic factors associated with the development of cervical cancer precursor lesions in women living with HIV in Africa. 2017.

53. Boccalon M, Tirelli U, Sopracordevole F, Vaccher E. Intra-epithelial and invasive cervical neoplasia during HIV infection. EurJ Cancer. 1996;32A(13):2212-7.

54. Freitas BC, Suehiro TT, Consolaro MEL, Silva VRS. (2015) MINI-REVIEW HPV infection and cervical abnormalities in HIV positive women in different regions of Brazil, a Middle-Income Country. Asian Pac J Cancer Prev. 2015;16(18):8085-91.

55. Denny LA, Franceschi S, De Sanjosé S, Heard I, Moscicki AB, Palefsky J. Human papillomavirus, human immunodeficiency virus and immunosuppression. Vaccine. 2012;30:168-74.

56. Ogembo RK, Gona PN, Seymour AJ, Park HS-M, Bain PA, Maranda L, et al. Prevalence of human papillomavirus genotypes among African women with normal cervical cytology and neoplasia: a systematic review and meta-analysis. PLoS ONE. 2015;10(4):e0122488. https://doi.org/10.1371/ journal.pone.0122488.

57. Derbie A, Mekonnen D, Yismaw G, Biadglegne F. Human papillomavirus in Ethiopia. Virus Disease. 2019.

58. Ouh YT, Min KJ, Cho HW, Ki M, Oh JK, Shin SY, et al. Prevalence of human papillomavirus genotypes and precancerous cervical lesions in a screening population in the Republic of Korea, 2014-2016. J Gynecol Oncol. 2018;29(1):1-10.

59. Bansal D, Elmi AA, Skariah S, Haddad P, Abu-Raddad LJ, Al Hamadi AH, et al. Molecular epidemiology and genotype distribution of Human Papillomavirus (HPV) among Arab women in the state of Qatar. J Transl Med. 2014;12:300.

60. Hanna J, Yassine R, El-Bikai R, Curran MD, Azar M, Yeretzian J, et al. Molecular epidemiology and socio- demographic risk factors of sexually transmitted infections among women in Lebanon. BMC Infect Dis. 2020;20:375.

\section{Publisher's Note}

Springer Nature remains neutral with regard to jurisdictional claims in published maps and institutional affiliations.
Ready to submit your research? Choose BMC and benefit from:

- fast, convenient online submission

- thorough peer review by experienced researchers in your field

- rapid publication on acceptance

- support for research data, including large and complex data types

- gold Open Access which fosters wider collaboration and increased citations

- maximum visibility for your research: over $100 \mathrm{M}$ website views per year

At BMC, research is always in progress.

Learn more biomedcentral.com/submissions 